\title{
Dynamics of sulfate reduction and sulfate-reducing prokaryotes in anaerobic paddy soil amended with rice straw
}

\author{
Ji-Zheng He $\cdot$ Xin-Zhan Liu $\cdot$ Yong Zheng • \\ Ju-Pei Shen $\cdot$ Li-Mei Zhang
}

Received: 21 July 2009 /Revised: 18 October 2009 / Accepted: 9 November 2009 / Published online: 26 November 2009

(C) Springer-Verlag 2009

\begin{abstract}
Incorporation of rice straw to soil is a common agricultural practice in rice cultivation. In anaerobic paddy soil, the complete mineralization of organic matter to $\mathrm{CH}_{4}$ and $\mathrm{CO}_{2}$ is accomplished by the sequential reduction of nitrate, ferric iron, sulfate, and methanogenesis. In order to estimate the temporal changes of sulfate-reducing prokaryotes (SRP) as decomposers of organic matters, the effects of rice straw amendment on the dynamics of sulfate reduction and SRP were investigated by combining the monitoring of $\mathrm{CH}_{4}$, sulfate, and organic acids with molecular tools such as soil DNA extraction, real-time PCR, cloning, sequencing, and phylogenetic analysis. The incorporation of rice straw into paddy soil significantly increased concentrations of sulfate, formate, acetate, propionate, and lactate and $\mathrm{CH}_{4}$ production. The rate of sulfate reduction in the straw-amended slurries was significantly higher than that in the unamended slurries. The $d s r A B$ gene copy numbers of SRP in the straw-amended soil slurries ranged from $4.26 \times 10^{6}$ to $1.96 \times 10^{8}$ per gram of dry soil, which were significantly higher than those in the unamended control ranging from $1.99 \times 10^{6}$ to $7.90 \times 10^{7}$ per gram of dry soil. Significant correlations were observed between SRP $d s r A B$ gene copy numbers and the concentrations of sulfate and acetate. Cloning and sequencing analyses showed a clear shift of
\end{abstract}

\footnotetext{
J.-Z. He $(\varangle) \cdot$ X.-Z. Liu $\cdot$ Y. Zheng · J.-P. Shen · L.-M. Zhang

State Key Laboratory of Urban and Regional Ecology,

Research Center for Eco-environmental Sciences,

Chinese Academy of Sciences,

18 Shuangqing Road,

Beijing 100085, China

e-mail: jzhe@rcees.ac.cn

X.-Z. Liu

Graduate University, Chinese Academy of Sciences,

Beijing 100049, China
}

SRP community structure between treatments and time. In the straw-amended slurries, Clostridia-like SRP significantly increased, while Deltaproterobacteria-like SRP (Sytrophobacter, Desulfobacterium, Desulfovibrio, and Desulfomonile) decreased during the incubation period. Novel uncultured SRP were abundant in the straw-amended slurries and changed during the incubation period.

Keywords Sulfate-reducing prokaryotes · Paddy soil · Acetate $\cdot$ Quantification $\cdot$ Real-time PCR .

Community structure $\cdot$ Clone libraries

\section{Introduction}

In paddy soil, methanogenesis is not the exclusive final step in anaerobic organic matter mineralization. Reductions of nitrate, ferric iron, and sulfate play important roles in the mineralization process, especially during the early phase of flooding of the rice fields when nitrate, ferric iron, and sulfate have not been completely depleted (Yao et al. 1999). Rice straw is one of the main carbon sources and commonly incorporated into the paddy soil to enhance soil fertility and crop productivity (Ponnumperuma 1984). After addition of rice straw into the paddy soil, the $\mathrm{C} / \mathrm{N}$ ratio changed from 18:1 to $24: 1$, indicating a relative large increase of soil carbon content and $\mathrm{C} / \mathrm{N}$ ratio (Conrad and Klose 2006). Rice straw increased concentration of available nutrients and microbial biomass (Shibahara and Inubushi 1997). It also increased copies of bacterial and archaeal 16S rRNA in anaerobic slurries of Italian paddy soil (Weber et al. 2001; Conrad and Klose 2006), suggesting microorganisms might have been actively involved in the mineralization of rice straw. 
The incorporation of rice straw into paddy soil has been a prevalent agronomic practice in southeast China (Shen et al. 2007). Rice straw consists of different biopolymers, including hemicellulose ( $26 \%$ to $35 \%$ ), cellulose ( $38 \%$ to $41 \%$ ), lignin (15\%), and water-soluble polysaccharides ( $8 \%$ ) (Grant 1998). There is a complex community with microbial populations interacting with each other for degrading these biopolymers in paddy soil. These microbial groups include hydrolytic, cellulolytic, fermenting, homoacetogenic, and syntrophic bacteria and acetate- and $\mathrm{H}_{2}$-utilizing sulfatereducing prokaryotes (SRP) and methanogenic archaea (Stams 1994; Chidthaisong and Conrad 2000a). Hydrolytic microorganisms convert the macropolymers to monomers and oligomers such as cellobiose and glucose firstly. These hydrolysates are then fermented by cellulolytic and associated saccharolytic organisms, yielding various organic acids, alcohols, $\mathrm{H}_{2}$, and $\mathrm{CO}_{2}$. The next step involves the conversion of organic acids to $\mathrm{H}_{2}, \mathrm{CO}_{2}$, and acetate. The final step in organic carbon mineralization involves the conversion of acetate, $\mathrm{H}_{2}$, and $\mathrm{CO}_{2}$ either into $\mathrm{CH}_{4}$ in methanogenic environments or to $\mathrm{CO}_{2}$ in the environments in which electron acceptors such as sulfate or ferric iron and the bacterial populations of sulfate reducers and iron reducers are present. Quantitatively, acetate is the main substrate for methanogenesis in freshwater sediments and for sulfate reduction in marine sediments (Ward and Winfrey 1985). Sulfate reducers (i.e., sulfate-reducing prokaryotes) can potentially compete with methanogens for acetate in freshwater sediments and have been shown to oxidize a part of the available acetate even at very low sulfate concentration (Smith and Klug 1981). There was also an association of methane oxidation with sulfate reduction under anaerobic conditions whereas it has not been documented in paddy fields (Barnes and Goldberg 1976; Panganiban et al. 1979).

However, so far, all information about the microbial community involved in this anaerobic degradation processes was obtained either by the investigation of bacterial community or by the characterization of methanogen community (Weber et al. 2001; Conrad and Klose 2006). Detailed information on the response of sulfate reduction and sulfate-reducing prokaryotes in rice straw-amended conditions is still lacking. In this study, we hypothesized that: (1) the application of rice straw could result in the temporal change of sulfate reduction in paddy soil slurries and (2) the application of rice straw might cause dynamic shifts in SRP abundance and community structure during the incubation period. Therefore, we tested this hypothesis by anaerobic incubation of paddy soil amended with rice straw and determination of the dynamics of sulfate reduction, formate, acetate, propionate, lactate, and $\mathrm{CH}_{4}$ production. The changes of SRP abundance and community structure during the degradation of rice straw in paddy soil slurries should be determined using combined real-time PCR, clone library, and sequencing analyses.

\section{Materials and methods}

Soil and straw samples

Soil samples were collected from the Taoyuan long-term Paddy Soil Experimental Station of Chinese Academy of Sciences $\left(28^{\circ} 55^{\prime} 49.8^{\prime \prime} \mathrm{N}, 111^{\circ} 26^{\prime} 25.7^{\prime \prime} \mathrm{E}\right)$, Hunan Province, China. It is a reddish clayey paddy soil, and the main characteristics have been described previously (Zheng et al. 2008; Liu et al. 2009). The soil samples were air-dried and sieved at $<2 \mathrm{~mm}$. Air-dried straw, originated from rice plants named Oryza sativa L cv. Jiahua-1 (Chen et al. 2008), was cut into pieces of $2 \mathrm{~cm}$ in length.

Preparation and incubation of slurries

The experimental setup was that described by Weber et al. (2001) and reported in Table 1: glass bottles (150-ml) were filled with $40 \mathrm{~g}$ of dry soil, $0.5 \mathrm{~g}$ of rice straw, and $40 \mathrm{ml}$ of deionized water. The bottles were gassed with $\mathrm{N}_{2}$ for $2 \mathrm{~min}$ and closed with butyl rubber stoppers. Then, the bottles were vigorously shaken by hand to homogenize the soil straw mixture and incubated for 4 weeks at $25^{\circ} \mathrm{C}$ in the dark. In control, rice straw was incubated as the above procedure. Gas and soil pore water samples from triplicate tubes of each treatment were collected at days 1, 2, 3, 4, 5, $6,7,14,21$, and 28 for chemical analysis. Triplicate soil samples were collected at day 1 and day 28 to extract DNA for molecular microbial analysis.

Analytical techniques

At the sampling days, gas samples $(0.5 \mathrm{ml})$ were taken from the headspace with a pressure-lock syringe after vigorously shaking the bottles by hands. The concentrations of $\mathrm{CH}_{4}$ were measured by a gas chromatograph equipped with a flame ionization detector and a molecular sieve $5 \AA$ column (Dionex, USA). Pore water samples $(3 \mathrm{ml})$ were taken with sterile syringe equipped with long needles. The pore waters were transferred to $5-\mathrm{ml}$ tubes and centrifuged for $15 \mathrm{~min}$ at $16,000 \times \mathrm{g}$ at $4^{\circ} \mathrm{C}$. The supernatants were collected and stored at $-20^{\circ} \mathrm{C}$ until further analysis. Prior to analysis, the samples were filtered through a $0.2-\mu \mathrm{m}$ membrane filter. Sulfate concentration was measured by ion chromatography equipped with an AS14 column and an ECD50 conductivity detector (Dionex, USA). Organic acids such as formate, acetate, propionate, and lactate were analyzed by high-performance liquid chromatography (Dionex, USA). 
Table 1 The setup and sampling method of the paddy soil slurry experiment

\begin{tabular}{|c|c|c|c|c|c|c|}
\hline \multirow[t]{2}{*}{ Treatment } & \multicolumn{2}{|l|}{ Sampling } & \multirow[t]{2}{*}{ Nomination } & \multicolumn{2}{|l|}{ Content } & \multirow[t]{2}{*}{$\mathrm{ddH}_{2} \mathrm{O}(40 \mathrm{ml})$} \\
\hline & Type & Time & & Dry soil (40g) & Rice straw $(0.5 \mathrm{~g})$ & \\
\hline Control & $\begin{array}{l}\text { Gas and soil } \\
\text { pore water }\end{array}$ & $\begin{array}{c}\text { Days } 1,2,3,4,5,6 \text {, } \\
7,14,21 \text {, and } 28\end{array}$ & / & - & + & + \\
\hline \multirow[t]{3}{*}{ Unamended paddy soil slurry } & Soil & Day 1 & SUS1 & + & - & + \\
\hline & & Day 28 & SUS28 & & & \\
\hline & $\begin{array}{l}\text { Gas and soil } \\
\text { pore water }\end{array}$ & $\begin{array}{c}\text { Days } 1,2,3,4,5,6 \\
7,14,21, \text { and } 28\end{array}$ & / & & & \\
\hline \multirow[t]{3}{*}{ Straw-amended paddy soil slurry } & Soil & Day 1 & SAS1 & + & + & + \\
\hline & & Day 28 & SAS28 & & & \\
\hline & $\begin{array}{l}\text { Gas and soil } \\
\text { pore water }\end{array}$ & $\begin{array}{c}\text { Days } 1,2,3,4,5,6 \\
7,14,21, \text { and } 28\end{array}$ & / & & & \\
\hline
\end{tabular}

\section{Soil DNA extraction}

Soil DNA was extracted from $0.5 \mathrm{~g}$ of fresh paddy soil slurry with the FastDNA ${ }^{\circledR}$ SPIN Kit for Soil (MP Biomedicals, USA) as recommended by the manufacturer. The extracted DNA was evaluated on a $1 \%$ agarose gel, and the concentration and purity of the extracts were estimated by spectrophotometry (NanoDrop, USA).

\section{Quantification analysis of $d s r A B$ genes by real-time PCR}

Abundances of SRP were determined by quantitative real-time PCR analysis based on dissimilatory (bi)sulfite reductase genes $(d s r A B) \alpha$-subunit on an iCycler iQ5 thermocycler (Bio-Rad, USA) according to the protocols described previously (Liu et al. 2009). In short, quantitative PCR was carried out with the DSRp2060F and DSR4R primers as follows: for initial denaturation, 2 min at $95^{\circ} \mathrm{C}$; 40 cycles of $10 \mathrm{~s}$ at $95^{\circ} \mathrm{C}, 30 \mathrm{~s}$ at $50^{\circ} \mathrm{C}$, and $30 \mathrm{~s}$ at $72^{\circ} \mathrm{C}$. The DNA concentration was 5 to $10 \mathrm{ng}$ for each reaction. Triplicates for standard and unknown DNA samples were performed on a single plate. The results were analyzed using the $\mathrm{iQ}^{\mathrm{TM}} 5$ software (Bio-Rad, USA). Copy numbers were log-transformed to normalize the values prior to statistical analysis.

Construction of the $d s r A B$ gene clone library and RFLP analysis

Amplifications of the $d s r A B$ gene were processed with the primer set DSRAB_F (5'-ACSCACTGGAAGCACG GYGG-3') and DSRAB_R (5'-GTAGCAGTTWCCGCAG WACAT- $3^{\prime}$ ) as described previously, which produced a 1.9-kb fragment (Schmalenberger et al. 2007). The 50- $\mu$ l reaction mixture consisted of $5 \mu 110 \times$ Ex Taq buffer, $4 \mu 1$ dNTPs $(2.5 \mathrm{mM}), 0.3 \mu \mathrm{l}$ Ex Taq HS $\left(5 \mathrm{U} \mu \mathrm{l}^{-1}\right.$; Takara, Japan), $0.5 \mu \mathrm{l}$ bovine serum albumin $(25 \mathrm{mM}), 0.5 \mu 1$ of each primer $(10 \mu \mathrm{M}), 3 \mu \mathrm{l}$ of template DNA (5-10 ng), and $36.2 \mu \mathrm{l}$ distilled $\mathrm{H}_{2} \mathrm{O}$. PCR amplification was carried out with the following conditions: three minutes at $94^{\circ} \mathrm{C}$; and 35 cycles of $1 \mathrm{~min}$ at $94^{\circ} \mathrm{C}, 1 \mathrm{~min}$ at $60^{\circ} \mathrm{C}$, and $3 \mathrm{~min}$ at $72^{\circ} \mathrm{C}$; and a final extension at $72^{\circ} \mathrm{C}$ for $10 \mathrm{~min}$. The PCR products were subjected to electrophoresis on a $1 \%$ agarose gel, and the expected fragment was gel-purified by the Wizard $^{\circledR}$ SV Gel and PCR Clean-Up System (Promega, USA). Four clone libraries of $d s r A B$ gene were constructed from the DNA extractions at days 1 and 28 from the strawamended and unamended paddy soil slurries. The purified PCR products were ligated into the pGEM-T Easy Vector (Promega, USA) and transformed into the Escherichia coli JM109 competent cells (Takara, Japan) according to the manufacturer's instructions. The expected PCR products were screened by the vector-specific primer set SP6 and T7. Approximate 100 positive colonies were randomly selected from each library for restriction fragment length polymorphism (RFLP) analyses using the restriction enzyme Mbo I. The digested products were analyzed by $2.5 \%$ agarose gel electrophoresis at $37^{\circ} \mathrm{C}$ for $2 \mathrm{~h}$. The RFLP patterns were analyzed by the software Quantity One (Bio-Rad, USA) and grouped according to the different band patterns.

Sequencing and phylogenetic analysis

At least one clone representative of each RFLP pattern was selected. The part encoding the $\alpha$-subunit ( $800 \mathrm{bp}$ ) of the dissimilatory sulfate reductase was sequenced on the ABI3700 sequencer (Applied Biosystems, USA). The homology analysis of deduced amino acid sequences of dissimilatory sulfate-reductase $\alpha$-subunit (DsrA) was performed with the software DNAMAN version 6.0. (Lynnon Biosoft, USA). The sequences showing more than $80 \%$ amino acid identity were grouped into the same operational taxonomy unit (OTU). The representative 
sequences of each OTU were aligned and analyzed using Clustal X 1.81 (Thompson et al. 1997). Phylogenetic tree was constructed with MEGA version 4.0 using neighborjoining method with bootstrap value of 1,000 (Tamura et al. 2007). The sequences in different OTUs were deposited in the GenBank nucleotide sequence database under accession numbers from FJ472864 to FJ472887.

\section{Statistical analysis}

The differences in concentrations of $\mathrm{SO}_{4}{ }^{2-}$, organic acids, and $\mathrm{CH}_{4}$ between treatments were statistically evaluated using one-way analysis of variance under significant differences $P<0.05$ using SPSS 13.0 statistical package. Bivariate correlation analyses were carried out to link SRP $d s r A B$ gene copy numbers and concentrations of sulfate, organic acids, and $\mathrm{CH}_{4}$.

\section{Results}

Reduction of sulfate

The sulfate concentration in the straw-amended slurries was significantly higher $(P<0.05)$ than that in the unamended slurries from 1 to 14 days (Fig. 1a). The rates of sulfate reduction calculated during the active period of sulfate utilization were $0.12 \mathrm{mM} \mathrm{d}^{-1}$ and $0.10 \mathrm{mM} \mathrm{d}^{-1}$ in the straw-amended and unamended slurries, respectively. Sulfate of the unamended paddy soil slurries was completely
Fig. 1 Temporal changes of sulfate (a), formate (b), acetate $(\mathbf{c})$, propionate $(\mathbf{d})$, lactate (e), and $\mathrm{CH}_{4}$ (f) in rice straw-amended (filled circle) and unamended (open circle) paddy soil slurries $($ bars $=\mathrm{SD}$, $n=3$ ) a

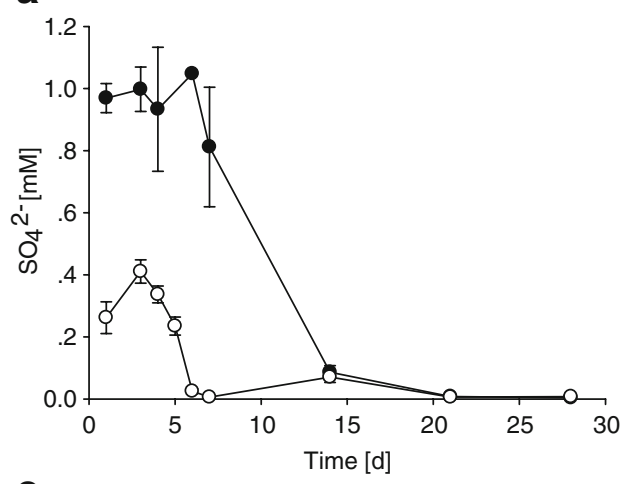

C
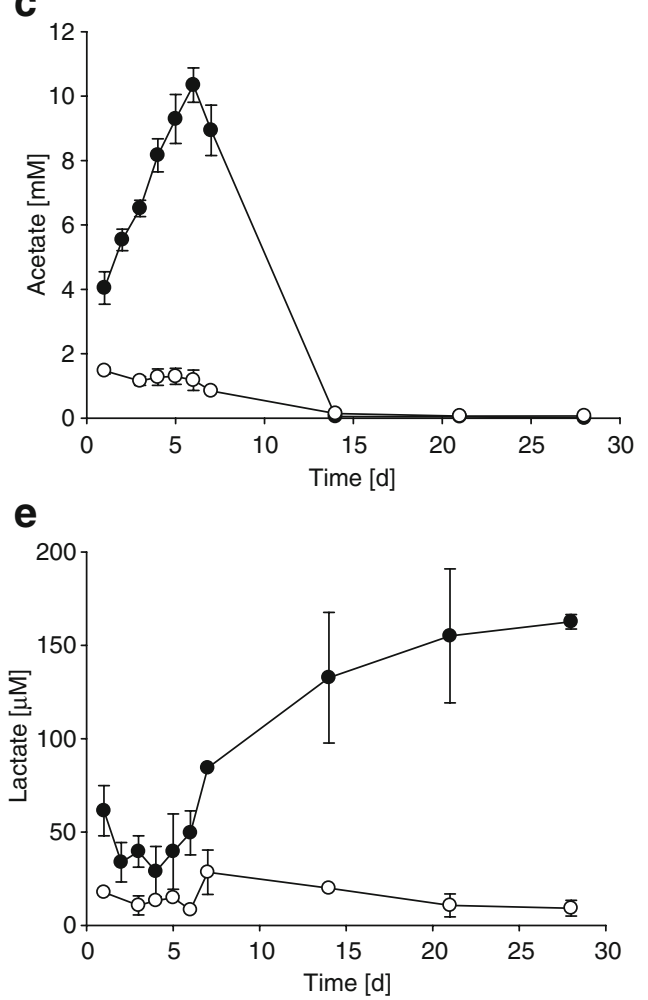
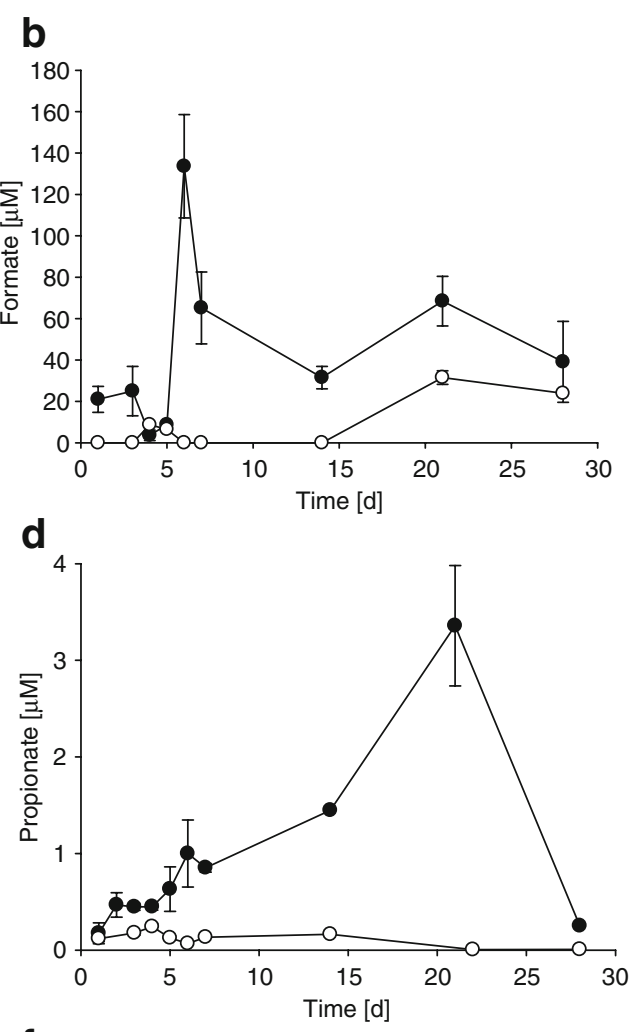

f

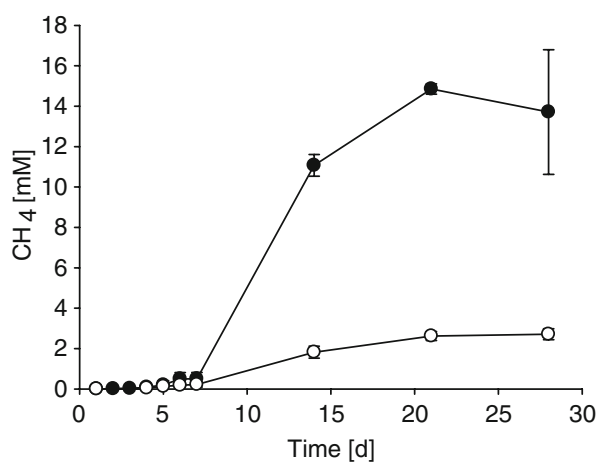


reduced at about day 7. Application of rice straw delayed the completion of sulfate reduction until day 14. The sulfate concentration was approximately $1 \mathrm{mM}$ after 1 day of incubation in the straw-amended slurries, while initial sulfate concentration in the unamended slurries changed from 0.2 to $0.4 \mathrm{mM}$ in the first 3 days. There was a 6-day lag before sulfate started decreasing in the amended slurries compared with a 3-day lag in unamended slurries.

Accumulation of organic acids and $\mathrm{CH}_{4}$ production

Acetate was found in high concentrations compared with the concentrations of other organic acids in all samples (Fig. 1c). Acetate concentration in the straw-amended slurries was significantly higher $(P<0.05)$ than that in the unamended slurries from day 1 to day 7 . In the unamended slurries, the acetate concentration decreased from $1.5 \mathrm{mM}$ at day 1 to approximately 0 at day 14 . In the straw-amended slurries, up to $10.3 \mathrm{mM}$ acetate transiently accumulated with a maximum at day 6 , but thereafter, acetate turnover progressed more rapidly than in the unamended slurries. Thus, acetate depletion was also complete at day 14 . Formate, propionate, and lactate concentrations in the straw-amended slurries were significantly higher $(P<0.05)$ than those in the unamended control from day 1 to day 28 (Fig. 1b, d, and e). Application of rice straw stimulated significant increment $(P<0.05)$ of $\mathrm{CH}_{4}$ production compared with the unamended slurries after day 7 (Fig. 1f). The rate of $\mathrm{CH}_{4}$ production in straw-amended slurries was $0.96 \mathrm{mmol} \mathrm{l}^{-1} \mathrm{~d}^{-1}$, which was six times higher than in the unamended slurries with $0.16 \mathrm{mmol} \mathrm{l}^{-1} \mathrm{~d}^{-1}$.

\section{Abundance of $d s r A B$ gene}

The $d s r A B$ gene copy numbers of SRP in the straw-amended paddy soil slurries, ranging from $4.26 \times 10^{6}$ to $1.96 \times 10^{8}$ per gram of dry soil, was significantly higher $(P<0.05)$ than those in the unamended slurries ranging from $1.99 \times 10^{6}$ to $7.90 \times 10^{7}$ per gram of dry soil at day $1,14,21$, and 28 (Table 2). After 1 day incubation, the $d s r A B$ gene copy numbers of SRP in the straw-amended slurries were greater than that in the unamended control. The $\operatorname{dsr} A B$ gene copy numbers of SRP in both straw-amended and unamended slurries decreased significantly $(P<0.05)$ from day 1 to day 14 , while increased significantly $(P<0.05)$ from day 14 to day 28. Bivariate correlation analyses demonstrated that the SRP $d s r A B$ gene copy numbers had significant correlations with concentrations of sulfate and acetate (Table 3).

\section{Community structure of SRP}

Four clone libraries were constructed from the SAS1, SAS28, SUS1, and SUS28. Phylogenetic trees of SRP
Table 2 Temporal changes of sulfate-reducing prokaryotes $d s r A B$ gene copy numbers in anaerobic Chinese paddy soil slurries amended and unamended with rice straw

\begin{tabular}{lll}
$d s r A B$ gene copy number (copies g ${ }^{-1}$ dry soil) & $\begin{array}{l}\text { Contrast } \\
\text { (SAS vs SUS) }\end{array}$ \\
$\begin{array}{ll}\text { Straw-amended slurry } \\
\text { (SAS) }\end{array}$ & $\begin{array}{l}\text { Unamended slurry } \\
\text { (SUS) }\end{array}$ & \\
\hline
\end{tabular}

Day $1 \quad 1.96 \times 10^{8} \pm 6.26 \times 10^{7} \mathrm{a}^{\mathrm{a}} \quad 7.90 \times 10^{7} \pm 4.76 \times 10^{7} \mathrm{a} \quad * *$ Day $14 \quad 4.26 \times 10^{6} \pm 1.81 \times 10^{6} \mathrm{~b} \quad 1.99 \times 10^{6} \pm 9.69 \times 10^{5} \mathrm{~b} \quad * *$ Day $216.55 \times 10^{6} \pm 1.30 \times 10^{6}$ bc $1.72 \times 10^{6} \pm 2.82 \times 10^{5} \mathrm{~b} * *$ Day $28 \quad 1.85 \times 10^{7} \pm 5.50 \times 10^{6} \mathrm{c} \quad 8.27 \times 10^{6} \pm 1.77 \times 10^{6} \mathrm{c} \quad * *$

\footnotetext{
${ }^{\mathrm{a}}$ Mean $\pm \mathrm{SD}, n=3$. Values within the same column followed by the same letter do not differ at $P<0.05$

**Values differ significantly at $P<0.05$ between straw-amended slurry and unamended slurry
}

$d s r A B$ gene sequences and related sequences are shown in Fig. 2. All SRP $d s r A B$ gene sequences fell within six clusters, affiliated to Deltaproteobacteria, Clostridia/ Archaeoglobus, and uncultured SRP. More than half of the $d \operatorname{sr} A B$ gene sequences $(51.5 \%$ of the total clone numbers, Table 4) were closely related to uncultured SRP. Cluster 2 and cluster $3(34.9 \%$ of the total numbers, Table 4) belonged to Gram-positive SRP of Clostridia or Archaeoglobus. Cluster 1 (13.6\% of the total numbers, Table 4) was affiliated to Deltaproteobacteria, composed of the families Syntrophobacteraceae, Syntrophaceae, Desulfobacteraceae, and Desulfovibrionaceae. Phylogenetic analysis of $d s r A B$ gene sequences revealed pronounced changes between treatments and time in the relative abundance of different SRP clusters (Table 4). In the straw-amended slurries, uncultured SRP of cluster 4 were the dominant SRP groups. In the unamended slurries, however, members of uncultured SRP of cluster 5 and cluster 2 of Clostridia became abundant. The proportions of uncultured SRP of clusters 5 and 6 increased during the incubation period in both straw-amended and unamended slurries, while the abundance of clusters 1,2 , and 4 decreased during the incubation period.

Table 3 Correlation analyses between the SRP $d s r A B$ gene copy numbers and concentrations of sulfate, organic acids, and $\mathrm{CH}_{4}$ in paddy soil

\begin{tabular}{lll}
\hline & $P$ value & Pearson correlation coefficient \\
\hline $\mathrm{SO}_{4}{ }^{2-}$ & 0.029 & 0.759 \\
Formate & $\mathrm{NS}$ & -0.177 \\
Acetate & 0.009 & 0.839 \\
Propionate & $\mathrm{NS}$ & -0.172 \\
Lactate & $\mathrm{NS}$ & 0.033 \\
$\mathrm{CH}_{4}$ & $\mathrm{NS}$ & -0.698 \\
\hline
\end{tabular}

NS not significant $P>0.05$ 


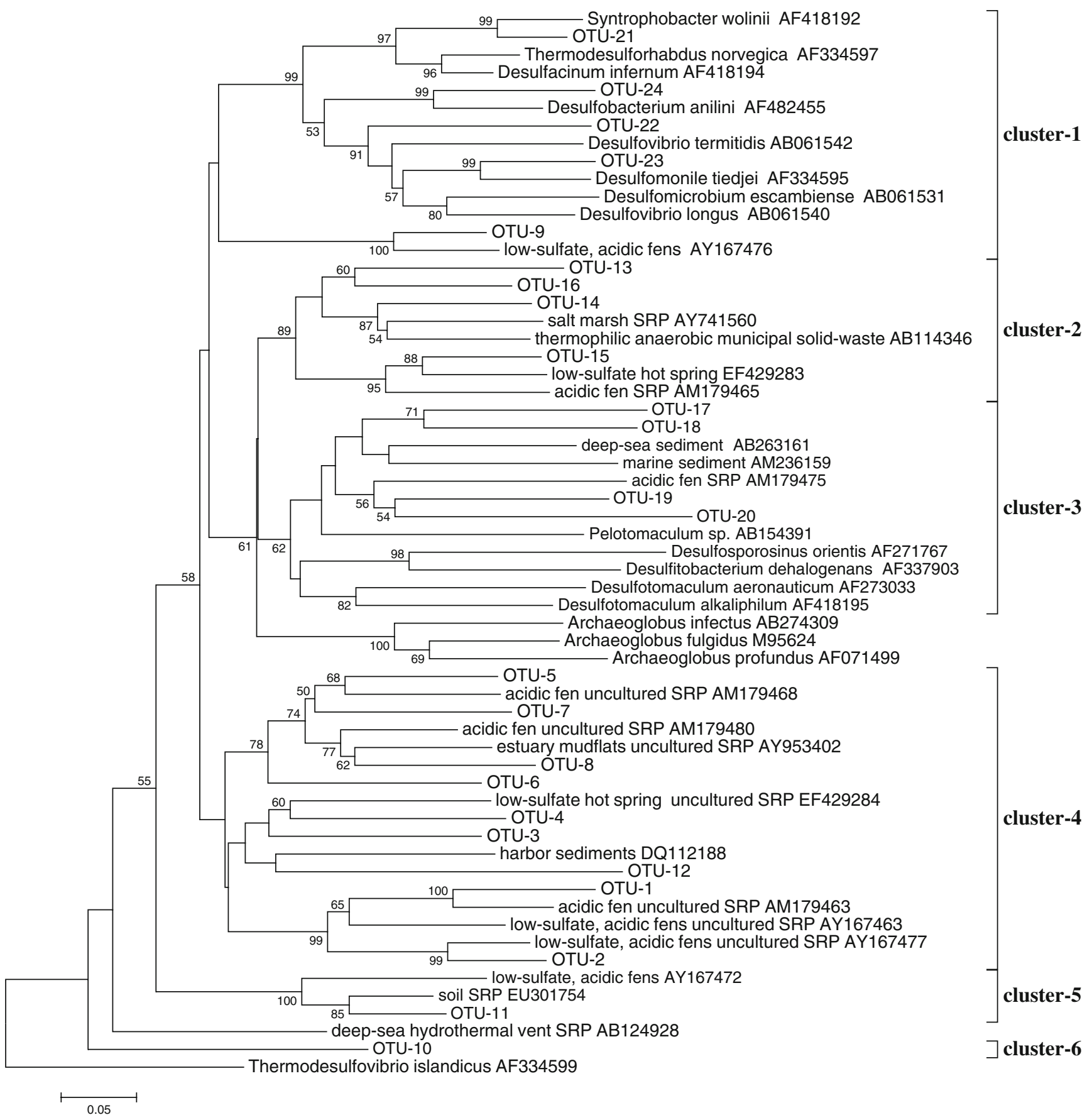

Fig. 2 Phylogenetic trees based on the protein sequences of the dissimilatory (bi)sulfite reductase $\alpha$-subunit (DsrA) retrieved from the straw-amended and unamended paddy soil slurries. Bootstrap values of $>50 \%$ based on 1,000 replicates are indicated by the numbers at the nodes

\section{Discussion}

Temporal change of sulfate

In our experiment, the productions of sulfate, formate, acetate, propionate, lactate, and $\mathrm{CH}_{4}$ were significantly higher in the straw-amended slurries than in the unamended control, which was in accordance with previous observation that application of organic carbon into freshwater wetlands could stimulate sulfate reduction, organic acids, and $\mathrm{CH}_{4}$ emission (Feng and Hsieh 1998; Glissmann and Conrad 2000). The sulfate concentration in the straw-amended slurries after $1 \mathrm{~d}$ incubation was approximately $0.9 \mathrm{mM}$, which was much higher than that of $0.3 \mathrm{mM}$ in the unamended slurries. It was due to the high sulfate concentration of $0.5 \mathrm{mM}$ measured in the control treatment 
Table 4 Relative abundance (\%) of major phylogenetic SRP clusters in $d s r A B$ gene clone libraries in both straw-amended and unamended paddy soil slurries

\begin{tabular}{|c|c|c|c|c|c|c|c|}
\hline & \multirow[t]{2}{*}{ OTU } & \multicolumn{4}{|c|}{ Clone library $(\%)^{\mathrm{a}}$} & \multirow[t]{2}{*}{ Tota } \\
\hline \multicolumn{2}{|c|}{ Phylogenetic group } & & SAS1 & SAS28 & SUS1 & SUS28 & \\
\hline Cluster 1 & Deltaproteobacteria & OTU-9, 21-24 & 20.9 & 13.3 & 16.6 & 4.0 & 13.6 \\
\hline Cluster 2 & Clostridia/Archaeoglobus & OTU-13, 14, 15, 16 & 25.0 & 23.3 & 33.3 & 20.0 & 25.2 \\
\hline Cluster 3 & Clostridia/Archaeoglobus & OTU-17, 18, 19, 20 & 8.3 & 13.3 & 4.2 & 12.0 & 9.7 \\
\hline Cluster 4 & Uncultured SRP & OTU-1-8,12 & 33.3 & 26.7 & 16.7 & 12.0 & 22.4 \\
\hline Cluster 5 & Uncultured SRP & OTU-11 & 8.3 & 16.7 & 29.2 & 48.0 & 25.2 \\
\hline Cluster 6 & Uncultured SRP & OTU-10 & 4.2 & 6.7 & 0.0 & 4.0 & 3.9 \\
\hline
\end{tabular}

${ }^{a}$ Clone library: $S A S 1$ straw-amended paddy soil slurry at day 1, SAS28 straw-amended paddy soil slurry at day 28, SUS1 straw-unamended paddy soil slurry at day 1, SUS28 straw-unamended paddy soil slurry at day 28

only with rice straw in our experiment. Because of the significantly higher sulfate concentration from straw amendment, soil redox potential (Eh) might become elevated. This made sulfate reduction thermodynamically endergonic. Hence, it is reasonable that sulfate started decreasing after a 6-day lag in the straw-amended slurries compared with a 3-day lag in the unamended slurries.

\section{Temporal change of organic acids}

In paddy soil, decomposition of rice straw served as an important source of organic matter for SRP growth in the anaerobic process (Chidthaisong and Conrad 2000b). Application of rice straw stimulated the immediate accumulation of fermentation products during the incubation period. In the detected organic acids, acetate was in most abundance during the decomposition of rice straw, whereas propionate showed the lowest concentration. This result was different from a previous study that found propionate was also an important intermediate following acetate (Glissmann and Conrad 2000). The unamended slurries also exhibited a lower amount of organic acids than the amended slurries, suggesting that, even without straw, the organic matter of paddy soil can be degraded with production of organic acids during anaerobic incubation.

Abundance of SRP in straw-amended paddy soil slurries

Addition of rice straw also resulted in a significantly higher SRP $d s r A B$ gene copy numbers in the straw-amended paddy soil slurries compared with the unamended slurries, indicating the important roles of carbon substrate to stimulate the growth of $d s r A B$-containing SRP. The SRP $d s r A B$ gene copy numbers had significant correlations with acetate concentration and sulfate concentration, respectively. This suggested that acetate and sulfate concentrations were important factors in controlling SRP abundance in the paddy soil slurries, and acetate was the most active intermediate organic acid in terms of its concentration. The higher copy numbers of $d s r A B$ gene in the straw-amended slurries than that in the unamended slurries may be due to the large SRP $d s r A B$ gene copy numbers in the straw itself. The decrease of the $\operatorname{dsr} A B$ gene copy numbers from day 1 to day 14 was paralleled by the depletion of sulfate. Then, the $d s r A B$ gene copy numbers increased from day 14 when the paddy soil slurries were in methanogenic steady state. Possible explanations for these results include: (1) sulfate was not the limiting factor to SRP growth; (2) SRP can survive by fermentation in syntrophism with methanogens under low-sulfate condition (Oude-Elferink et al. 1994; Hadas and Pinkas 1995). The $d s r A B$ gene copy numbers at day 28 both in the straw-amended and unamended paddy soil slurries were one order of magnitude less than those at day 1 . This trend was similar to the shift of the bacterial $16 \mathrm{~S}$ rRNA gene copies both in the straw-amended and unamended slurries detected by using FISH probe Univ1392 targeting all organisms (Weber et al. 2001). It might imply that SRP grow syntrophically with many other eubacteria as well as archaea.

Dynamics of SRP community structure in straw-amended soil slurries

In addition to significantly decreasing in SRP abundance from day 1 to day 28 , a corresponding shift was observed in SRP community composition between day 1 and day 28 in straw-amended paddy soil slurries. Most pronounced was a temporal increase of Clostridia in cluster $3(8.3 \%$ to $13.3 \%)$ and uncultured SRP in clusters 5 and $6(12.5 \%$ to $23.4 \%)$. Gram-positive sulfate reducers, Clostridia, have been mostly isolated from aquifers, rice root, and freshwater environments and grew well in low sulfate concentration (Ikeeaga et al. 2003; Leloup et al. 2006). It was observed that Gram-positive SRP could grow well in the low-sulfate condition by fermentation together with methanogens (Sass et al. 1997). In our study, the sulfate concentration 
decreased and $\mathrm{CH}_{4}$ production enhanced during the incubation period. It was therefore reasonable that more abundant Gram-positive SRP were present. Cluster 1 was similar to Sytrophobacter, Desulfobacterium, Desulfovibrio, and Desulfomonile in Deltaproteobacteria. Sytrophobacter-like and Desulfobacteraceae-like SRP were acetoclastic, which lived by acetotrophic syntrophism with methanogens by the degradation of various aromatic hydrocarbons and other organic substrates (Boone and Bryant 1980; Schnell et al. 1989; Kniemeyer et al. 2003). These acetate-utilizing sulfate reducers could not outcompete with acetoclastic methanogens at high concentration of acetate (Achtnich et al. 1995). Considering the rapid decrease in acetate concentration and the stimulation in $\mathrm{CH}_{4}$ production after day 7 , these acetate-utilizing sulfate reducers could not outcompete with methanogens, and the relative abundance of cluster 1 decreased during the incubation period. Novel uncultured SRP with high relative abundance in clone libraries affiliated with those retrieved from the freshwater environment such as acidic fen (Schmalenberger et al. 2007), estuary mudflats (Leloup et al. 2006), low-sulfate hot spring microbial mat (Dillon et al. 2007), and soil (Hansel et al. 2008). The reason of increasing relative abundances of clusters 5 and 6 and decreasing relative abundance of cluster 4 during the incubation period is not clear. Considering the significantly higher concentration of lactate in straw-amended slurries in this study, the lactate-utilizing SRP may play a role in the later incubation period (Qatibi et al. 1990). In a word, it deserves further studies to elucidate if these novel uncultured SRP have the similar lifestyle to Gram-positive sulfate reducers Clostridia and acetate-utilizing sulfate reducers, or they possessed different growth mechanisms (Liu et al. 2009).

\section{Conclusions}

In conclusion, our results have demonstrated the potential effect of rice straw on the dynamics of sulfate reduction and sulfate-reducing prokaryotes in the paddy soil slurries. The application of rice straw significantly enhanced concentrations of sulfate, formate, acetate, propionate, and lactates and stimulated $\mathrm{CH}_{4}$ production. The $d s r A B$ gene copy numbers in the straw-amended paddy soil slurries were significantly higher than that in the unamended slurries. The $d s r A B$ gene coy numbers had significant correlation with concentrations of sulfate and acetate. Sulfate and acetate concentrations were the important factors controlling SRP population size, but sulfate was not the limiting factor for SRP growth. Significant differences in SRP community structure between treatments and time were detected. Novel uncultured SRP were abundant in the straw-amended paddy soil slurries and shifted remarkably during the incubation period. Their growth mechanisms deserve further studies to better understand their functions in the degradation of organic matters in the paddy soil slurries.

Acknowledgements This work was supported by the Chinese Academy of Sciences (KZCX1-YW-0603, KZCX2-YW-408), the Ministry of Science and Technology (2005CB121105), and the Natural Science Foundation of China (40701087, 40871129).

\section{References}

Achtnich C, Bak F, Conrad R (1995) Competition for electron donors among nitrate reducers, ferric iron reducers, sulfate reducers, and methanogens in anoxic paddy soil. Biol Fertil Soils 19:65-72

Barnes RO, Goldberg ED (1976) Methane production and consumption in anoxic marine sediments. Geology 4:297-300

Boone DR, Bryant MP (1980) Propionate-degrading bacterium, Sytrophobacter wolinii sp. nov., gen. nov., from methanogenic ecosystems. Appl Environ Microbiol 40:626-632

Chen XP, Zhu YG, Xia Y, Shen JP, He JZ (2008) Ammonia-oxidizing archaea: important players in paddy rhizosphere soil? Environ Microbiol 10:1978-1987

Chidthaisong A, Conrad R (2000a) Turnover of glucose and acetate coupled to reduction of nitrate, ferric iron and sulfate and to methanogenesis in anoxic rice field soil. FEMS Microbiol Ecol 31:73-86

Chidthaisong A, Conrad R (2000b) Pattern of non-methanogenic and methanogenic degradation of cellulose in anoxic rice field soil. FEMS Microbiol Ecol 31:87-94

Conrad R, Klose M (2006) Dynamics of the methanogenic archaeal community in anoxic rice soil upon addition of straw. Eur J Soil Sci $57: 476-484$

Dillon JG, Fishbain S, Miller SR, Bebont BM, Habicht KS, Webb SM, Stahl DA (2007) High rates of sulfate reduction in a low-sulfate hot spring microbial mat are driven by a low level of diversity of sulfate-reducing microorganisms. Appl Environ Microbiol 73:5218-5226

Feng JN, Hsieh YP (1998) Sulfate reduction in freshwater wetland soils and the effects of sulfate and substrate loading. J Environ Qual 27:968-972

Glissmann K, Conrad R (2000) Fermentation pattern of methanogenic degradation of rice straw in anoxic paddy soil. FEMS Microbiol Ecol 31:117-126

Grant RF (1998) Simulation of methanogenesis in the mathematical model ECOSYS. Soil Biol Biochem 30:883-896

Hadas O, Pinkas R (1995) Sulfate reduction in the hypolimnion and sediments of Lake Kinneret, Israel. Freshw Biol 33:63-72

Hansel CM, Fendorf S, Jardine PM, Francis CA (2008) Changes in bacterial and archaeal community structure and functional diversity along a geochemically variable soil profile. Appl Environ Microbiol 74:1620-1633

Ikeeaga M, Asakawa S, Muraoka Y, Kimura M (2003) Bacterial communities associated with nodal roots of rice plants along with the growth stages: estimation by PCR-DGGE and sequences analysis. Soil Sci Plant Nutr 49:591-602

Kniemeyer O, Fischer T, Wilkes H, Glockner FO, Widdel F (2003) Anaerobic degradation of ethylbenzene by a new type of marine sulfate-reducing bacterium. Appl Environ Microbiol 69:760-768

Leloup J, Quillet L, Berthe T, Petit F (2006) Diversity of the $d s r A B$ (dissimilatory sulfite reductase) gene sequences retrieved from 
two contrasting mudflats of the Seine estuary, France. FEMS Microbiol Ecol 55:230-238

Liu XZ, Zhang LM, Prosser JI, He JZ (2009) Abundance and community structure of sulfate reducing prokaryotes in a paddy soil of southern China under different fertilization regimes. Soil Biol Biochem 41:687-694

Qatibi AI, Bories A, Garcia HL (1990) Effects of sulfate on lactate and $\mathrm{C}_{2^{-}}, \mathrm{C}_{3}$-volatile fatty acid anaerobic degradation by a mixed microbial culture. Antonie Van Leeuwenhoek 58:241-248

Oude-Elferink SJWH, Visser A, Hulshoff Pol LW, Stams AJM (1994) Sulfate reduction in methanogenic bioreactors. FEMS Microbiol Rev 15:119-136

Panganiban AT, Patt TE, Hart W, Hanson RS (1979) Oxidation of methane in the absence of oxygen in lake water samples. Appl Environ Microbiol 37:303-309

Ponnumperuma FN (1984) Straw as a source of nutrients for wetland rice. In: IRRI. (ed) Organic matter and rice. International Rice Research Institute, Los Baños, Philippines, pp 117-136

Sass H, Cypionka H, Babenzien HD (1997) Vertical distribution of sulfate-reducing bacteria at the oxic-anoxic interface in sediments of the oligotrophic Lake Stechlin. FEMS Microbiol Ecol 22:245-255

Schmalenberger A, Drake HL, Kusel K (2007) High unique diversity of sulfate-reducing prokaryotes characterized in a depth gradient in an acidic fen. Environ Microbiol 9:1317-1328

Schnell S, Bak F, Pfennig N (1989) Anaerobic degradation of aniline and dihydroxybenzenes by newly isolated sulfate-reducing bacteria and description of Desulfobacterium aniline. Arch Microbiol 152:556-563

Shen MX, Yang LZ, Yao YM, Wu DD, Wang JG, Guo RL, Yin SY (2007) Long-term effects of fertilizer managements on crop yields and organic carbon storage of a typical rice-wheat agroecosystem of China. Biol Fertil Soils 44:187-200

Shibahara F, Inubushi K (1997) Effect of organic matter application on microbial biomass and available nutrients in various types of paddy soils. Soil Sci Plant Nutr 43:191-203

Smith RL, Klug MJ (1981) Electron donors by sulphate-reducing bacteria in eutrophic lake sediments. Appl Environ Microbiol 42:116-121

Stams AJM (1994) Metabolic interactions between anaerobic bacteria in methanogenic environments. Antonie Van Leeuwenhoek 66:271-294

Tamura K, Dudley J, Nei M, Kumar S (2007) MEGA4: Molecular Evolutionary Genetics Analysis (MEGA) software version 4.0. Mol Biol Evol 24:1596-1599

Thompson JD, Gibson TJ, Jeanmougin F, Higgins DG (1997) The Clustal_X windows interface: flexible strategies for multiple sequence alignment aided by quality analysis tools. Nucleic Acids Res 24:4876-4882

Ward DM, Winfrey MR (1985) Interactions between methanogenic and sulfate-reducing bacteria in sediments. Adv Aquat Microbiol 3:141-179

Weber S, Stubner S, Conrad R (2001) Bacterial populations colonizing and degrading rice straw in anoxic paddy soil. Appl Environ Microbiol 67:318-1327

Yao H, Conrad R, Wassmann R, Neue HU (1999) Effect of soil characteristics on sequential reduction and methane production in sixteen rice paddy soils from China, the Philippines, and Italy. Biogeochemistry 47:269-295

Zheng Y, Zhang LM, Zheng YM, Di HJ, He JZ (2008) Abundance and community composition of methanotrophs in a Chinese paddy soil under long-term fertilization practices. J Soils Sediments 8:406-414 